\title{
X-Ray Focusing: Techniques and Applications
}

\author{
Ali Khounsary, ${ }^{1}$ Stephen L. O’Dell, ${ }^{2}$ and Gene Ice ${ }^{3}$ \\ ${ }^{1}$ Argonne National Laboratory, Argonne, IL, USA \\ ${ }^{2}$ NASA Marshal Space Flight Center, Huntsville, AL, USA \\ ${ }^{3}$ Oak Ridge National Laboratory, Oak Ridge, TN, USA \\ Correspondence should be addressed to Ali Khounsary, amk@aps.anl.gov \\ Received 31 December 2010; Accepted 31 December 2010 \\ Copyright (C) 2010 Ali Khounsary et al. This is an open access article distributed under the Creative Commons Attribution License, \\ which permits unrestricted use, distribution, and reproduction in any medium, provided the original work is properly cited.
}

This Special Issue of X-Ray Optics and Instrumentation comprises ten review papers and six research articles, which collectively offer a broad overview of X-ray focusing techniques and applications in laboratory measurements, in synchrotron beamlines, and in X-ray astronomy. Focusing enables not only more intense illumination for reduced exposure time and higher signal-to-noise ratio, but higher spatial resolution through true imaging. Although X-ray focusing is accomplished through the application of some basic physical principles, such as reflection (mirrors), refraction (lenses), and diffraction (crystals or zone plates), stringent performance requirements coupled with physical, mechanical, environmental, and manufacturability imperatives or limitations make the task technically challenging. The diverse X-ray focusing techniques and applications covered in this Volume provide a glimpse into the scope, challenges, and future of this expanding field.

\section{Acknowledgments}

We wish to sincerely thank the authors who contributed to this volume and the numerous reviewers for their indispensible suggestions and comments. We also thank the Journal's Chief Editor, Professor. Carolyn MacDonald, for her support, and the staff at Hindawi Publications for their invaluable assistance in preparing this special issue.

Ali Khounsary

Stephen L. O'Dell

Gene Ice 